\title{
Aesthetics of numerical proportions in human cosmetic surgery (Assessment of nasolabial angle in patients undergoing rhinoplasty ${ }^{1}$ before and after surgery)
}

\author{
Zhaleh Shahbazi ${ }^{1}$, Hossein Ardalani ${ }^{2}$
}

\begin{abstract}
Beauty is a universal phenomenon and debate over what constitutes beauty particularly beauty to human body, has raged since philosophy began. The beauty of individual features depends on "ideal" proportions, and it is suggested that expressing beauty in terms of geometry is possible. Assessment of some used parameters in facial surgeries and harmony of various facial features are essential to surgeon, who requires facial analysis. One of these parameters, is nasolabial ${ }^{2}$ angle, in patients undergoing rhinoplasty. This study based on theoretical definitions of beauty and proportions performed the search for the application of this numerical proportions in modern cosmetic surgery. Present study has selected 23 samples (16 (69.5\%) female and 7 (30.5\%) male) from patients who undergoing rhinoplasty, By a surgeon. The nasolabial angle was measured in these patients from their lateral profile photographs with adobe Photoshop cc, pre and post surgery. Ideal post operative angle was $111.54 \pm 26.5$ degrees from this study. 18.8 increase in male and $14.68^{\circ}$ increase in female is seen. There was no significant difference between men and women.
\end{abstract}

Keywords: aesthetic, numerical proportions, rhinoplasty, nasolabial angle

\section{INTRODUCTION}

Esthetic is taken from the Greek word (Aisthanesthai), which means sensory perception (6).

For Plato, something of our symmetry is included in what he means by beauty, and the long mathematical approach to symmetry starts with the Timaeus (2). Evidence from historical texts and art dating back to the Renaissance period show that appreciation of ideal facial proportions has persisted for ages (3).

Jahanbin et al. hypothesized that values of certain measured proportions in beautiful faces are likely to approximate the divine proportion (4). The rule of golden proportions has been proposed in an attempt to define anatomical beauty (5). A new challenge to face recognition is facial plastic surgery these surgeries alters struggle to identify a person face after surgery (6).

There is historical evidence for cosmetic surgery in ancient times (7).

Cosmetic surgery is increasingly popular, globally (8). In contemporary society, the media are largely responsible for providing universal Yardsticks (9).

Reports and recent comments suggest that beauty has become one of the main Iranians concerns. One of the Englishlanguage site, the report quoted the world Health Organization (WHO), called Iran, capital cosmetic surgery (10). Despite its subjective natures (beauty), we can attempt to define, measure and explain the captivating phenomenon of beauty by describing it numerically and geometrically (11).

The number of people undergoing these plastic surgeries is increasing every day (6).

\footnotetext{
1. Rhinoplasty: Nose surgery

2. Nasolabial angle (NLA): Angle between bisecting Axis of the nostril and vertical facial plane (12)
}

\footnotetext{
PHD student philosophy of ART, Department of Art and Architecture, Hamedan Branch, Islamic Azad University, Iran.

2 Assistant professor, Department of ART and Architecture, Hamedan Branch, Islamic Azad University, Iran.
}

Received: 27 Feb 2018, Accepted: 12 May 2018

\author{
Correspondence: Hossein Ardalani \\ Assistant professor, Department of ART and Architecture, Hamedan Branch, Islamic \\ Azad University, Iran.
}

E-mail: zhshahbazi2020@gmail.com

(C) 2018 by the authors; licensee Modestum Ltd., UK. This article is an open access article distributed under the terms and conditions of the Creative Commons Attribution License (http://creativecommons.org/licenses/by/4.0/). 
A satisfactory cosmetic results and optimal healing is the aim of aesthetic surgery (9).

It is essential therefore to be able to assess the possible satisfaction that can be expected after an aesthetic surgery procedure and to determine the beauty of the final results as precisely as possible (ibid).

All facial parts are of absolute importance for the perception of facial beauty. However, the nose has a special importance because it occupies the central position in the face (13).

One of the most important parameters in the nose to measure, is tip rotation. An arbitrary range of 90 to 115 degrees for the nasolabial angle (in connection with the nasal tip rotation) is usually (ibid).

By measuring this parameter we can understand the far and near obtained number in various researches from the ideal proportion, and examine the role of this parameter in assessing postoperative.

In a study that was conducted in 37 patients in 2008, prospective analysis of 37 patient submitted to rhinoplasty, were 13 (36\%) men and 24 (64\%) women. The nasolabial angle was measured and compared, before and after surgery, in lateral profile pictures. An average increase of $8.6^{\circ}$ in the nasolabial angle was observed (14).

In other study, in Turkish people (56 male and 59 female), this angle was achieved whit out surgery about $98.91 \pm$ $2.32^{\circ}$ in female (31). Other study was in 102 adults (41 man and 61 women) in the south Indian population with obtained an ideal angle about $99.76^{\circ}$. The sexual difference was not observed (15).

One study was conducted in 2006 on lateral photographs, were taken of 100 volunteers (60 woman and 40 man).

Nasolabial angle for female was average about $102.22^{\circ}$ and for male was $98.83^{\circ}(16)$.

Another relevant study was in Bangladeshi Garo male and female, without surgery. The mean value of nasolabial angle found in Garo (91.28 $\pm 12.98^{\circ}$ in males and $91.92^{\circ} \pm 8.90^{\circ}$ in females). The sexual difference was not observed (17).

Another study was done in 20 patients ( 18 female and 2 male) pre operative nasolabial angle was $99 \pm 8.82^{\circ}$ and post operative nasolabial angle was $104.5 \pm 8.25^{\circ}$ (12).

Another study was done in 45 patients ( 24 female and 21 male). There was no significant difference between men and women. Average of nasolabial angle was $96.1 \pm 9.7$ (32). Since ancient times, the supporters of beauty as an objective and measurable property attempted to state ideal proportions, or beauty canons, for the human body and its part (18). A face is beautiful and shows harmonious features if the individual components are proportional (19).

A new challenge to face recognition is facial plastic surgery (6).

While Iran ranks first in cosmetic surgenes and has been called the capital of world's rhinoplasty $(7,10)$ and the facial proportions are essential to facilitate surgeon who requires facial analysis in the diagnosis and treatment planning (19). Therefore, the relevant parameters can be a way for satisfaction after surgery.

A satisfactory cosmetic results and optimal healing is the aim of aesthetic surgery (9).

This study first, examine the historical context and the origin of aesthetic beauty and numerical proportions philosophically, and after the history of cosmetic surgery, to assess use one of the parameter of this proportions, in contemporary cosmetic surgery, have chosen a sample of 23 individuals who underwent rhinoplasty in a beauty clinic and pay to measure the angle. Between the lip and nose in these patients before and after surgery, to achieve the ideal angle in these patients

Finally compare offers the results of this study with previous research, to express application of the proportionality in modern surgery.

Present study with retrospective approach, puts the overview origin of these proportions, and pays to use nasolabial angle which are widely used in proportions face surgery.

Pick that angle due to the fact that the measure is less error.

For less error the environmental variables, patients were selected from a surgeon. The samples were 23 people, 7 men and 16 women with images of similar quality and position (lateral and forward head, siting on a chair) group were similar in age class.

\section{BEAUTY AND NUMBERS}

Generally, philosophical ideas about beauty and art has existed since Plato onward across the west (1).

Perceived through the senses of aesthetic was employed first by Alexander Gottleb Baumgarten in a book on Latin name is Aesthetica (ibid).

Body measurement were used by the old Egyptains to execute their famous sculptures and painting Facial measurements were first performed by the Greeks as part of total body measurements for the same purpose (9). History of human life, has been full of goddess worship or beautiful creatures of course, this is not to say that, what kind of beauty is worshiped as it is without change (20). 
Rules defining the relationships between various face and body features were more clearly formulated by scholars and artists of the Renaissance based on classical Greek canons (9).

From the era of the ancient Greeks, through to the Renaissance, and the present day, mathematicians, scientists, architects, artists, and cosmetic surgeons have been intrigued by the ubiquitous nature of the divine proportion and its correlation with aesthetics (11). In Plato's classic aesthetics, sensible beauty is shadows, effects, or idea from conceptional beauty (1).

Debate over what constitutes beauty, Particularly beauty of the human body, has raged since philosophy began (9).

The old adage beauty lies in the eye of the beholder $(4,21,22)$. Stipulated that the individual judgements were paramount and needed to be regarded since the assessment of facial attractiveness is very complex (21). Aristotle puts just once benchmark offers a beautiful tragedy and it is when it says, tragedy should not be too long that it does not have enough memory to record, Nor too short, the seriousness out (23).

This piece shows that beauty can be defined using the length (more volume) and ratio (ibid).

It appears that youth and symmetry are the most highly prized attributes of beauty (9).

Beauty and facial attractiveness are easy to identify but difficult to quantify (11).

Modern life style, constantly influenced by media exposure of universal beauty standard, gives aesthetic values a pivotal role in social life (24).

Since ancient times, the supporters of beauty as an objective and measurable property attempted to state ideal proportions, or beauty canons for the human body and its parts (18).

The harmonic body shop -as perceived by the human eye- is a result of a series of definite numeric relationships between the sizes and positions of various segments of the body (22).

Furthermore geometric patterns and the numbers associated with them give symbolic role to this system with holy concepts that permanent archetype or as jung, draw primordial role in the proper pattern with the artistic language, until be under standardable for human (25).

The golden ratio also known as the divine proportion, is considered by many to be the key to the secret of aesthetics, attraction and human beauty $(11,19)$.

Renaissance artist, as Leonardo da vinci, Leon Battista Alberti, Alberecht Duerer and piero della Francesca, reformulated and documented the classic canons, have been used for centuries in art by sculptors, painters, and are a rough working guide for plastic surgeons (18).

More precisely, aesthetic judgments can be considered a subset of evaluative judgments (9).

Although certain characteristics of human faces are broadly considered more attractive (e.g., symmetry, average eness), people also routinely disagree with each other on the relative attractiveness of faces (26).

\section{COSMETIC SURGERY}

The first record history of plastic surgery in the world is related to $600 \mathrm{BC}$, In Iran recorded history of plastic surgery goes back to 1000 before, it means the time of $1 \mathrm{bm}$ sina which introduced the first repair of the tendon. According to recent statistics by the American society of plastic surgery in 2008 more than one million facial plastic surgeries were performed, with a growth of $162 \%$ in ten years (27).

Some theorist believe that feminization of cosmetic surgery is likely to be short-lived historically.

Statistics and tends are also confirmed so that is indicated a gradual increase in men and Non- whites (7)

Geometrical standards are of particular importance for aesthetic- the medical branch involved in the artificial increase of one's, beauty status (22).

Rhinoplasty, establishes a pleasant connection between nose and other facial components, in addition to their proportions in the nose. One of the most important criteria is tip rotation, that this amount is determined on angle base between nose and lip. This angle is between the two lines below:

1. The line passes from front and back of nostril

2. Vertical line to the horizontal plane when patient back forward

We can easily measure mentioned angle with our available software.

To take effective steps the more accurate way of doing, rhinoplasty.

Nasolabial angle is located between clomella ${ }^{3}$ and upper lip.

\footnotetext{
${ }^{3}$. Clomella: it's the lowest nose section such as column between nostrils.
} 


\section{RESULTS}

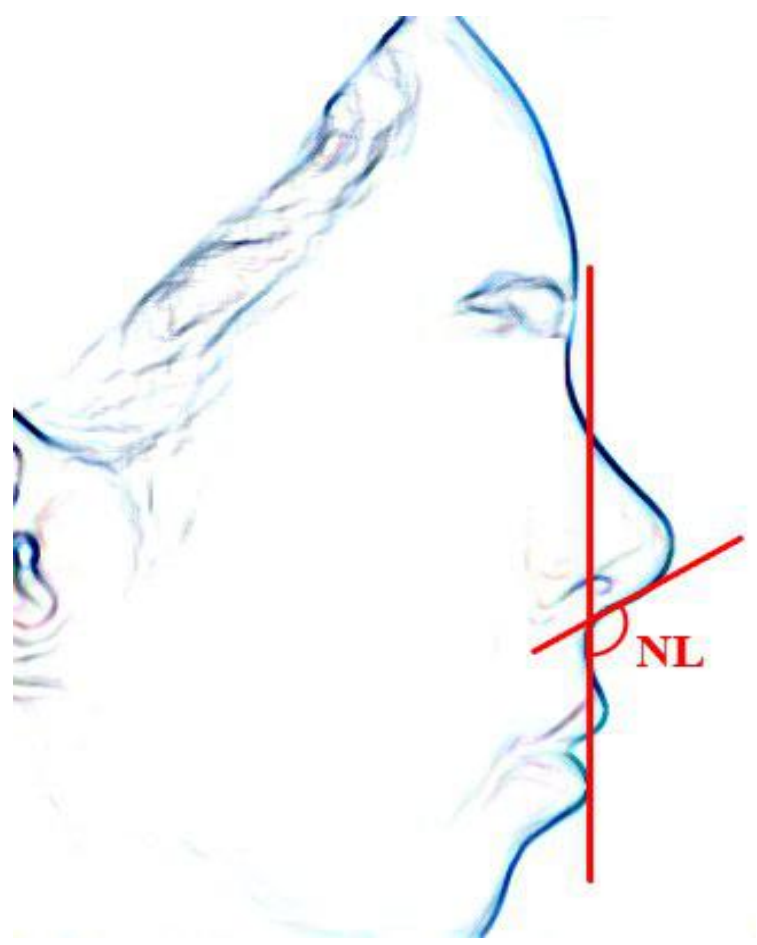

Figure 1: Assessment of Nasolabial angle

Obtained results from this study indicated the ideal angle was about $111.54 \pm 26.5^{\circ}$ after surgery. Average change this angle in men was $18.8^{\circ}$ increase and in women $14.68^{\circ}$ increase. Also from this study, we conclude that the average postoperative angle was significant sexual difference, despite the variety preoperative angle between male and female patients. Preoperative angle in men showed a more limited range, and obtained about 90-100', but in women were a wider range, and showed $87-110^{\circ}$.

After surgery, nasolabial angle was 106-117 in men and 106-114 in women, that indicated fixed numerical range of the procedure which can be considered an ideal range in patients undergoing rhinoplasty to evaluate the postoperative results.

Results in Figure 1- Maximum change was indicative of 24 degree and minimum change was 12 degree obtained results represent the average change had 18.8 degree in male patients.

Table 1: Pre and post operative nasolabial angle and its changes in men

\begin{tabular}{cccc}
\hline No & Preoperative angle & Postoperative & The change \\
\hline 1 & $90^{\circ}$ & $114^{\circ}$ & $24^{\circ}$ \\
2 & $90^{\circ}$ & $112^{\circ}$ & $22^{\circ}$ \\
3 & $90^{\circ}$ & $110^{\circ}$ & $20^{\circ}$ \\
4 & $90^{\circ}$ & $107^{\circ}$ & $17^{\circ}$ \\
5 & $93^{\circ}$ & $117^{\circ}$ & $24^{\circ}$ \\
6 & $94^{\circ}$ & $106^{\circ}$ & $12^{\circ}$ \\
7 & $100^{\circ}$ & $113^{\circ}$ & $13^{\circ}$ \\
\hline
\end{tabular}


Table 2: Pre and post operative angle and its changes in woman

\begin{tabular}{cccc}
\hline No & Preoperative angle & Postoperative & The change \\
\hline 1 & $87^{\circ}$ & $110^{\circ}$ & $23^{\circ}$ \\
2 & $90^{\circ}$ & $106^{\circ}$ & $16^{\circ}$ \\
3 & $90^{\circ}$ & $109^{\circ}$ & $19^{\circ}$ \\
4 & $90^{\circ}$ & $112^{\circ}$ & $22^{\circ}$ \\
5 & $90^{\circ}$ & $113^{\circ}$ & $23^{\circ}$ \\
6 & $93^{\circ}$ & $110^{\circ}$ & $20^{\circ}$ \\
7 & $95^{\circ}$ & $107^{\circ}$ & $15^{\circ}$ \\
8 & $96^{\circ}$ & $113^{\circ}$ & $11^{\circ}$ \\
9 & $98^{\circ}$ & $114^{\circ}$ & $15^{\circ}$ \\
10 & $98^{\circ}$ & $115^{\circ}$ & $16^{\circ}$ \\
11 & $100^{\circ}$ & $115^{\circ}$ & $15^{\circ}$ \\
12 & $100^{\circ}$ & $106^{\circ}$ & $15^{\circ}$ \\
13 & $102^{\circ}$ & $115^{\circ}$ & $115^{\circ}$ \\
15 & $103^{\circ}$ & $110^{\circ}$ & $12^{\circ}$ \\
16 & $110^{\circ}$ & $121^{\circ}$ & $9^{\circ}$ \\
\hline
\end{tabular}

Results in Figure 2 Maximum change was 23 degree, one was unchanged.

Obtained results represent the average change had 14.68 degree in female patients.

Results from this study, were indicative more changes the postoperative angle in men. Range of preoperative angle in men was 90-100 degree and in women was about 87-110 degree. Average preoperative was 92.4 in men and 97.12 in women.

Postoperative angle was $111.54 \pm 26.5$ in both of them. Thus, as can be seen, changes of this angle was more in men because had they less preoperative angle.

Table 3: Pre and post operative nasolabial angle in woman and men and change extent

\begin{tabular}{cccccccc}
\hline Sex & $\begin{array}{c}\text { Preoperative angle } \\
\text { extent }\end{array}$ & $\begin{array}{c}\text { Postoperative angle } \\
\text { extent }\end{array}$ & $\begin{array}{c}\text { Average } \\
\text { preoperative }\end{array}$ & $\begin{array}{c}\text { Average post } \\
\text { operative }\end{array}$ & $\begin{array}{c}\text { Average of } \\
\text { change }\end{array}$ & $\begin{array}{c}\text { Average of whole } \\
\text { angle }\end{array}$ \\
\hline Men & $90-100$ & $106-117$ & 92.4 & 111.28 & 18.8 & $111.5 \pm 26.5$ \\
Women & $88-110$ & $106-114$ & 97.12 & 111.81 & 14.68 & $111.5 \pm 26.5$ \\
\hline
\end{tabular}

\section{DISCUSSION}

The aim of this study, was search about application of numerical proportions in contemporary cosmetic surgery.

For this purpose, one of the important parameters in pre and post rhinoplasty's surgery assessment, was selected. Nasolabial angle was selected for assessment of tip rotation as important factor for cosmetic surgeons, special and practical aim of this study was gain an ideal proportion as a measures to assessment before surgery, for the patient expection and after surgery to satisfaction surgery procedure.

Results, indicated relatively fixed number as on ideal proportion to assessment pre and post operative procedure.

The results have obtained in small samples of patients in a beauty clinic.

It is recommended to examine more patients and several beauty clinic in next study, to generalize and more value.

Compare that can be done between this study with previous research results, is both of before and after surgery, because some studies have evaluated the ideal angle in normal people without surgery, results from present study was compared with previous study results both of them (with surgery and without surgery).

From this perspective, preoperative angle in this study is closest to Garo's study (17), Average ideal angle was from this perspective, in this study, preoperative angle in men (90-100') with average about $92.4^{\circ}$, is closest to Garo's study results (91.28 in men), without surgery (17).

After that, our results is closest to Dua et al. study in 2010 (32), (96.1 \pm 9.1 ).

Preoperative angle in this study is closest to ozdemir, Uzun study in 2014 (28) $\left(98.91 \pm 10^{\circ}\right)$ in women.

Our study results about preoperative angle in women is also close to Dua et al. in 2010 (32) $\left(96.1 \pm 9.7^{\circ}\right)$.

Present study results about post operative angle in male and female patients under study is closest to pasinato's study in 2007 (14) $\left(107.6 \pm 7.5^{\circ}\right)$ and Garo's study in 2013 (females $107.57^{\circ}$ and male: $105.2^{\circ}$ ).

This study is also close to Meruane et al. in 2016 (12) (104.5 \pm 8.25$)$. 
Post operative angle obtained from this study is $111.54 \pm 26.5^{\circ}$, and has distance with Armijo et al. study results in 2015 (31) (93.4- 98.5 in male and $95.5 \pm 100^{\circ}$ in female). This study is away Kommi et al. study in 2015 (15) (99.76 \pm 15.35), but is close to across the whole, between two obtained proportion. Present study is close to Aghili et al. in 2016 (29) (102 \pm 10.22$)$ across the whole, this proportion had achieved without surgery in usual persons.

Garo's study was noted to European white skin people ideal angle without surgery. Present results study, after surgery is closest to their proportion without surgery. This is may be a marker the desire of Iranians to westernization their ideal proportions and their desire to correction facial proportion according to a normal western face standards. One of this research limitations, is ignore from Ethnicity, race and genetic features, factors.

Another research limitation is about age. In Aghili et al. study in Iran, the age factor was also taken in to account.

However, in this study, it reduce with age increasing. Another research limitation, was the small number of patients.

We hope so be considered in next studies. The used techniques were different in various researches. Some of them had used radiographic methods, some direct measurement such as Anthropometric methods and some methods were assessment of pictures and photos. It can be another limitation of this study which can be effective in the evaluation process.

Finally, this result can be achieved that an ideal proportion can be very useful and practical to assess patient's preoperative expectations and evaluate the results after surgery and satisfaction of cosmetic surgery process, but for the best results and make the right decisions, should be taken in to account ethnicity and genetic factors and age factors and other nose proportions with other face members until obtained proportion in accordance with the figure that is expected of a specific ethnicity, make it look more beautiful then before surgery.

\section{REFERENCES}

1. Esfandyari S. Implementation of aesthetics in the philosophy of Plato and Descartes. Journal of philosophy. 2013;41(1):67-84.

2. Llyod DR. Symmetry and Beauty in Plato. 2010;2:455-465. https://doi.org/10.3390/sym2020455

3. Tan KS, Oh SR, Priel A, Korn BS, Kikkawa DO. Surgical Anatomy of the Forehead, Eyelids, and mid face for the Aesthetic surgeon. Master Technoques in Ble phatoplasty and periorbital Rejuvenation. 2011:11-24.

4. Rupesh S, Rakesh S, Winner JJ, Kaimal A, John A, Palasannam M, Jeyaprakash V. The role of divine proportion in the perception of beauty: A Cross Sectional Study. Amrita Journal of Medicine. 2014;10(1):1-44.

5. Persaud D, P.O' Leary J. Fibonacci Series, Golden proportions, and the Human Biology. Austin Journal of surgery. 2015;2(5):1-7.

6. Umerdkar K, Wagh P, Bhoir A. Face Recognition System Invariant to Plastic Surgery. International Journal of Advanced Research in Computer and Communication Engineering. 2015;4(4):32-34.

7. Amir RK, Mehdi K. Women and beauty project (The study of subjective meanings in cosmetic surgery). Journal of women in Development and politics. 2013;11(4):478-453.

8. Tam KP, Ng HKS, Kim YH, Yeung VWL, Cheung FYL. Attitudes toward Cosmetic Surgery Patients: The role of Culture and Social Contact. The Journal of Social Psychology. 2012;152(4):458-479. https://doi.org/10.1080/00224545.2011.637997

9. Atiyeh BS, Hayek SN. Numeric Expression of Aesthetics and beauty. Aesth plast surge. 2008;32:209-216. https://doi.org/10.1007/s00266-007-9074-x

10. Sohrabi F, Mahmood Aliloo M, Rasooli Azad M. Check profile psychopathology plastic surgery Applicants. Journal of basic mental health. 2011;13(51):9-26.

11. Predergast PM. Facial Proportions. Advanced Surgical Facial Rejuvenation. 2012;2:15-22. https://doi.org/10.1007/978-3-642-17838-2_2

12. Meruane $M$, Fernanda Ayala $M$, Angelica G, Huidobro $M$, Andrades P. Reliability of Nasofacial Analysis Using Rhinobase Software. Aesth plast surg. 2016;40:149-156. https://doi.org/10.1007/s00266-015-0569-6

13. Naraghi $M$, Atari $M$, Asadollahi $H$. When Aesthetics, Surgery and psychology meet: Aesthetic Nasal proportions in patients having Rhinoplasty and Normal Adults. The surgery Journal. 2016;2:44-48. https://doi.org/10.1055/s0036-1579658

14. Pasinator $R$, Mocellin $M$, Carlini Arantes $M$, Serrato Coelbo $M$, Dall'lgna DP, Soccel AT. Intl. Arcb. Otorbinolaryngol. 2008;12(3):393-396.

15. Kommi PB, Venkatesan R, Keerthi N, Kumar S, Gopinath V. A Cephalometric Assessment of ideal Nasolabial angle Range for South Indian Pupulation. Journal of International Oral Health. 2016;8(2):205-207. 
16. Kim DW, Egan KK. Metrics of Nasal Tip Rotation: A Comparative Analysis. The American Laryngological, Rhinological and Otological Society. 2006:872-877.

17. Ferdousi MA, Almamun A, Banu LA, Paul S. Angular Photogrammetric Analysis of the Facial of the Adult Bangladeshi Garo. Advances in Anthropology. 2013;3(4):188-192. https://doi.org/10.4236/aa.2013.34026

18. Bottino A, Laurentini A. The analysis of facial beauty: an emerging area of research in pattern analysis. Lecture Notes in Computer Science. 2010;1:425-435. https://doi.org/10.1007/978-3-642-13772-3_43

19. Sadacharan MC Evaluation Various Facial Anthropometric proportions in Indian American Women. Facial Anthropometric proportions. Rev Arg de Ant Clin. 2016;8(1):10-17.

20. Balali E, Afshar kohan J. Beauty and money: Make up and surgery. Journal of women's cultural and social council. 2010;12(37):99-140.

21. SunilKumar LN, Kalpana SJ, Nazirkar GS, Singh S, Nagmode PS, Mukram Ali F. Assessment of facial Golden Proportions among North Maharashtian Population. Journal of International Oral Health. 2013;5(3):48-54.

22. Holman A. Psychology of Beauty: An Overview of the Contemporary Research Lines. Social psychology. 2011;28:81-94. Available at: http://www.Geeol.com

23. Gaut B, Lopes D. The Routledge Companion Aesthetics. Tehran Translation groups: 19. 2005.

24. Naraghi M, Atari M. Preliminary Findings on Gender Differences in Aesthetic Rhinoplasty patients: Body Appreciation and Appearance Comparisons. Otolaryngology Open J. 2015;1(1):7-12. https://doi.org/10.17140/OTLOJ-1-103

25. Nasr Abadi A, Porjafar M, Taghavaee A. Analyzing the role of Aesthetic geometry in the formation of Esfahan Chaharbagh urban space. 2011.

26. Germine L, Russell R, Bronstad PM, Smoller JW, Kwok H, Anthony SE, Nakayama K, Rhodes G, Wilmer JB. Individual Aesthetic Preferences for faces Are shaped mostly by Environments, Not Genes. Current Biology. 2015;25:1-6. https://doi.org/10.1016/j.cub.2015.08.048

27. Bottino A, Simone MDe, Laurentini A, Sforza C. A new 3D Tool for Planning Plastic Surgery. IEEE Transactions on Biomedical Engineering. 2012;59(12):1-14. https://doi.org/10.1109/TBME.2012.2217496

28. Uzun A, Ozdemir F. Morphometric analysis of nasal shapes and angles in young adults. Brazilian Journal of Otorh Inolaryngology. 2014;80(5):397-402. https://doi.org/10.1016/j.bjorl.2014.07.010

29. Aghili $H$, Tabatabaei SMA, Goldani Moghadam M, Jafarzadeh M, Samei R. Soft tissue Cephalometric nirms in Iranian normal subjects. International Journal of medical Research \& Health Sciences. 2016;5(4):149-155.

30. Sadacharan MC. Vertical and horizontal facial proportions of Indian American men. Anatomy and cell Biology. 2016;49:125-131. https://doi.org/10.5115/acb.2016.49.2.125

31. BS. Armijo, M. Brown, B. Guyuron, Defining the ideal nasolabial angle. 2015.

32. Dua V, Gupta S, Singh C. Evaluation of the nasolabial angle in the Indian population. Contemporary Clinical Dentistry. 2010;1(2):79-82. https://doi.org/10.4103/0976-237X.68595

$\diamond \diamond \diamond \diamond \diamond \diamond \diamond$

http://www.ejgm.co.uk 